\title{
Characteristic Identification Methodology for 2D Sheet Metal Components
}

\author{
Vijayakumar K, L.Prabhu, Tony O T, Akshith M S, Gokul Kannan
}

\begin{abstract}
In the computer-integrated production environment, computer-assisted process planning is a key area which analyses the Computer aided Design server collects information about design and converts it into the necessary information about manufacturing. To identify $2 D$ sheet shearing operations from the nested architecture provided by a wire frame template, a feature identification procedure has been suggested. Basically, the method uses geometric data to determine different groups of objects. Entity groups are categorized into a number of features for raw resources, a set of boundary features, and a set of interior features. There seems to be a special classification of the feature functions inclusion to both the set of boundary functions. Components (i.e. boundary elements set together with their inside feature set components) are lexicographically arranged. Based on the suggested categorization for shearing practices and using multiple feature sets, processing features were defined. The technique listed above, definitions are explained along with its principles. This is performed in the $C$ environment and from the DXF output directory of AutoCAD geometric information is retrieved.
\end{abstract}

Keywords :computer-integrated production, shearing practices, entity groups, sheet metal parts.

\section{INTRODUCTION}

Throughout CIMS, machine-aided design and production facilitated by software are essential components and the bridge is developed by CAPP[1]. A part's function identification is the foundation of CAPP as it analyzes a Computer aided design collects information about design and converts it into the necessary information about manufacturing[2].

Revised Manuscript Received on December 16, 2019.

Vijayakumar K *, Assistant Professor Department of Mechanical Engineering Aarupadai Veedu Institute of Technology, Vinayaka Mission Research Foundation. Email: vijayakumar@avit.ac.in.

L.Prabhu , , Associate Professor, Department of Mechanical Engineering Aarupadai Veedu Institute of Technology, Vinayaka Mission Research Foundation, Tamil Nadu, Chennai.

Tony O T, UG Student, Department of Mechanical Engineering Aarupadai Veedu Institute of Technology, Vinayaka Mission Research Foundation, Tamil Nadu, Chennai.

Akshith M S, UG Student, Assistant Professor Department of Mechanical Engineering Aarupadai Veedu Institute of Technology, Vinayaka Mission Research Foundation, Tamil Nadu,Chennai.

Gokul Kannan, UG Student, Department of Mechanical Engineering Aarupadai Veedu Institute of Technology, Vinayaka Mission Research Foundation, Tamil Nadu, Chennai.

\section{METHODOLOGY}

The method of collecting features and shearing activities is to fit the DXF code repository with the geometric entities. Hence, functions should be predefined in the function database Figure 1 illustrates the system's application flow briefly. Begin by developing the part that was converted as an input to DXF code. The code understands line by line by algorithm of attribute extraction to capture the code's coordinate and actual drawing.

The field of sheet metal parts feature identification is small, and many press operations are still to be defined for sheet metal components. Also, importance must be given to the idea of a nested format when specifying the features of the development[3]. The nested design concept was quantified in this paper when designing a method for shearing operations to identify characteristics.Manufacturing attributes are clearly defined for components produced in a CAD system are independent of activity and method operation as form factors in sheet metal elements, but depend on the form, amount as well as strength of the sheet metal components.

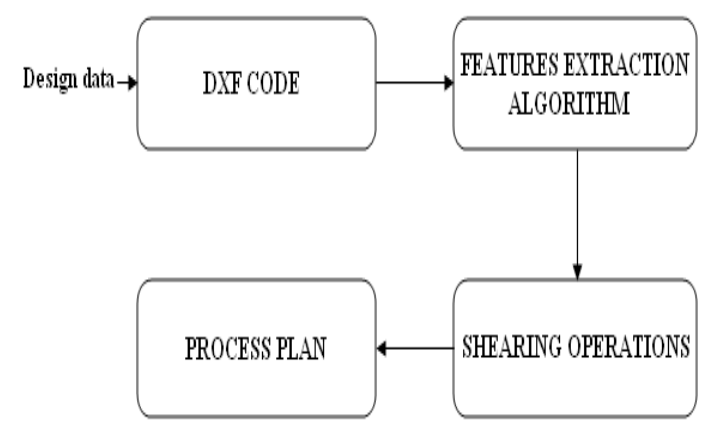

Fig. 1.Information flow of the system .

\section{A. Sheet Metal}

Today, the approach to successfully producing high-quality sheet metal parts is not just how it was made[4]. Most significantly, all the measures from the concept to the finished product in the full process chain are optimally planned. This holistic approach makes sure

- Production design requirements are taken into account.

- Software-oriented programming.

- The whole computer software is used in development.

- Sheet metal used in many applications, such as Car bodies, Medical tables, Airplane wings, Transformers and electric machines, Roofs for building and many other things. 


\section{B. Shearing Operations}

A traditional punch procedure is one in which the surface is pierced by a cylindrical punching tool, creating a hole. Figure 2 shows the shearing .

However, a range of operations are attainable to create totally different options[5]-[6]. The various Sheet metal operations are,

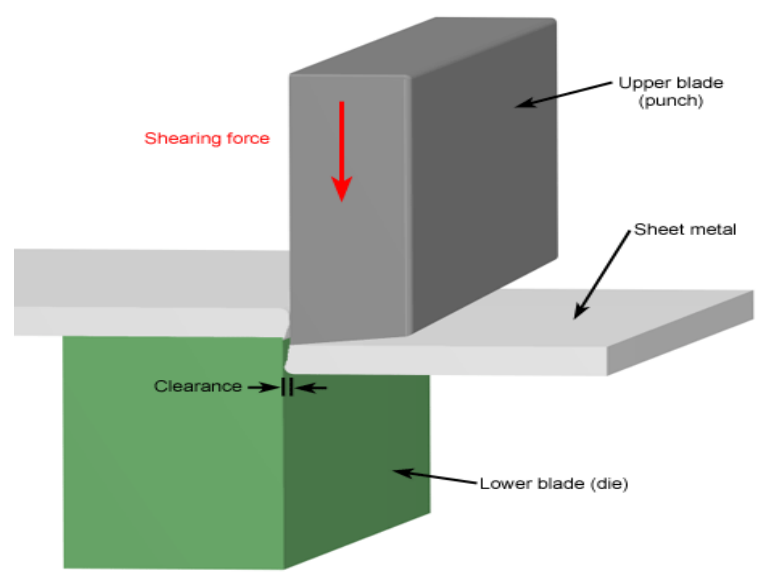

Fig. 2.Shearing.

- Piercing

- Blanking

- Lancing

- Notching

- Parting

- Cutoff

- Slitting

- Nesting

- Nibbling

- Shearing.

\section{ATTRIBUTE RECOGNITION}

\section{A. Terminology}

The given below concepts are the terminology of identification of features provided by taking into consideration the design of a nested explain of a reform 2D slip metal element.

Entitys $\rightarrow$ This corresponds to an arc (a), circle (c), line (l) or polyline (p), as revealed in Figure 3.

Features $\rightarrow$ A group of entities is called a feature in an prepared form that can be generated through press procedures. For examples, there are features in Figure 3 [11, $12, \ldots, 112],[113,114, \ldots, 122]$ and $[\mathrm{c} 1]$ are elements.

Feature set $(\mathrm{F}) \rightarrow$ Scope element of a set of elements ([ 1 , 13' ] shown in Figure 4) Shape graphs that are spatially disjointed.
4. Raw material feature set $(\mathrm{R}) \rightarrow$ An component of $\mathrm{R}$ is a function with a total probable length all along the $\mathrm{X}$ as well as Y directions. For example, in Figure 4[1].

Set of boundary functions $(B) \rightarrow$ between all features of $F$ are elements with a total estimated length all along the $\mathrm{X}$ along with/or $\mathrm{Y}$ directions, except for the characteristic present in $\mathrm{R}$ for a given element format.

Inside feature set $(\mathrm{N}) \rightarrow$ Components are those features $(\mathrm{F})$ members that are not in $\mathrm{R}$ and $\mathrm{B}$.

Concave edge $\rightarrow$ The excluded angle of edge is less than $180^{\circ}$ is known as concave edge. It is represented by (-).

Convex edge $\rightarrow$ The excluded angle of edge is greater than $180^{\circ}$ is known as convex edge. It is represented by $(+)$.

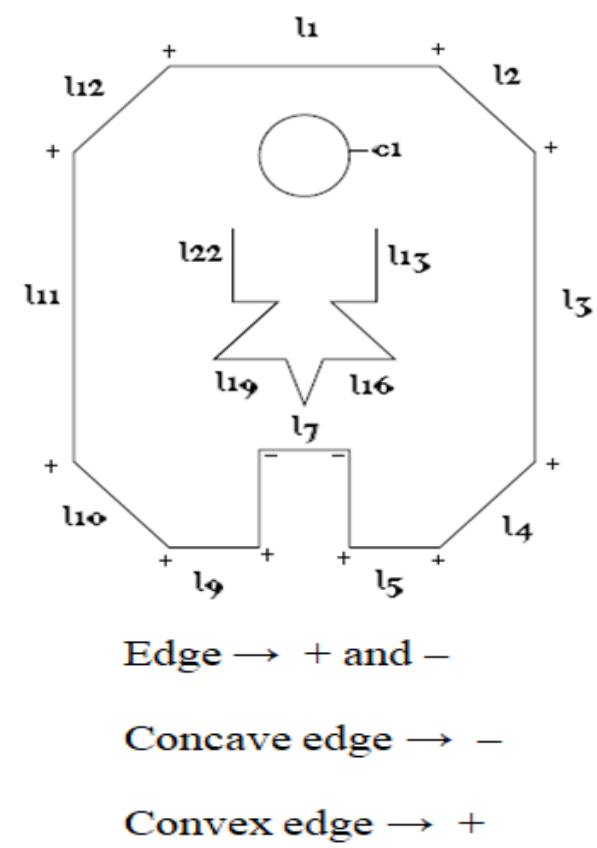

Fig. 3.Component and example for sheet metal layout definitions. 
1

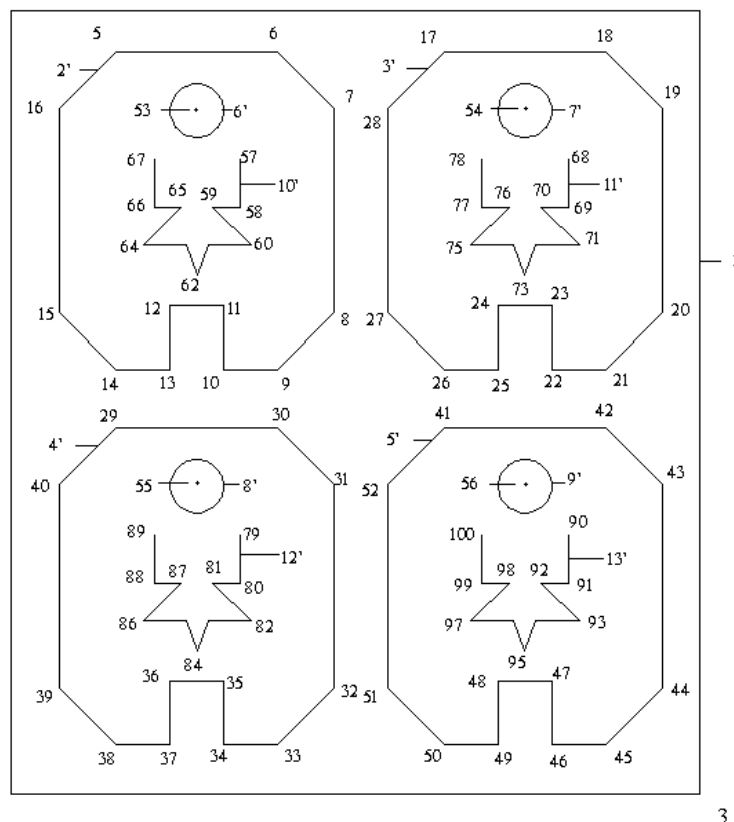

Fig. 4.Plan of component layout .

\section{B. Shearing Operation Features}

The Data development $\rightarrow$ Pre-processing of design data $\rightarrow$ Entity community category

Identify feature components $\rightarrow \mathrm{R}, \mathrm{B}$ and $\mathrm{N}$

Components Identification $\rightarrow$ Order of parent characteristics along with identification of child characteristics

Eradication of adjacent components directional relationship $\rightarrow$ Adjacent Components Directional Relationship table

Description to raw objects type $\rightarrow$ plate, strip or coil

Description of production characteristics $\rightarrow$ Shearing attributes

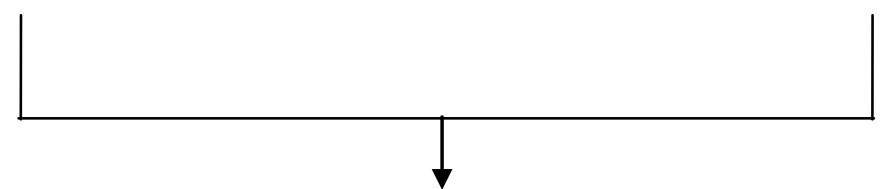

To proceeding

\section{PROCESSESS OF SHEARING ATTRIBUTES}

\section{A. Preprocessing of Geometric Data}

Because Geometric information is extracted from AutoCAD production directory of DXF (Drawing Exchange Format). The DXF consists of the following sections, headers, classes, tables, frames, entities, objects, and file ends. The DXF is analyzed and data is collected on the type of group of entities and Entities involved in the category of entities.

DXF FILE

DXF is possibly one of the vector formats that are most widely supported in the world today. DXF is rich in functionality, including: 3D object support, curves, text support, associative dimensioning, and is an easy to read format which is shown in the figure 5 .

GENERAL DXF FILE STRUCTURE

HEADER section

CLASSES section

TABLES section

BLOCKS section

ENTITIES section

OBJECTS section

END OF FILE.

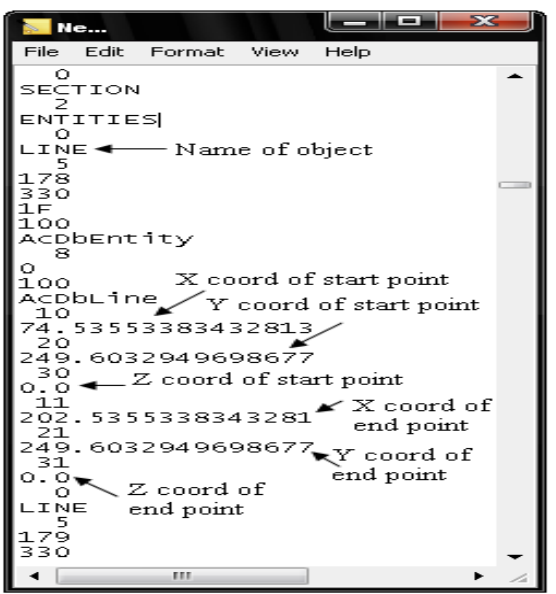

a)

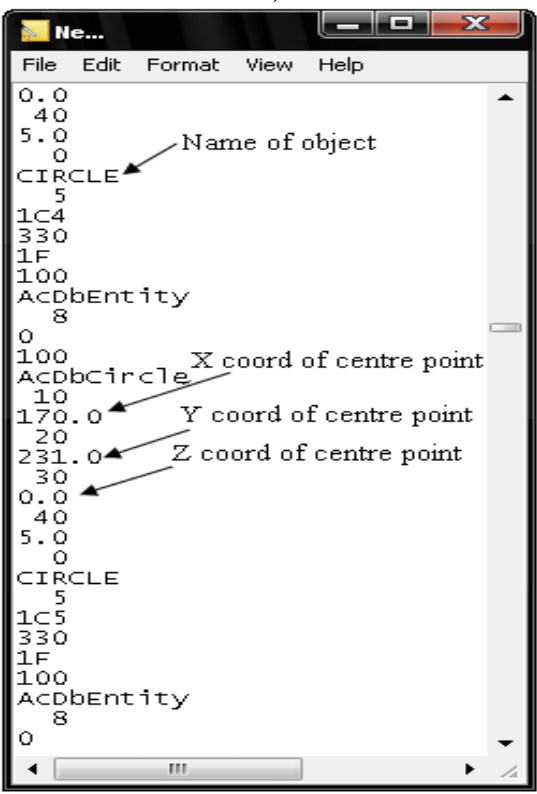

b)

Fig. 5.A)\& b)Format of DXF file .

\section{B. Classification of Components of a set of functions}

Classification scheme of group identification and product characteristics shown in the figure 6.The feature set $(\mathrm{F})$ elements are grouped into three separate feature sets, i.e.

Raw material feature set $(\mathrm{R})$, 
Boundary feature set (B) and

Inside feature set $(\mathrm{N})$,

Based on the concept of a set conceptual.

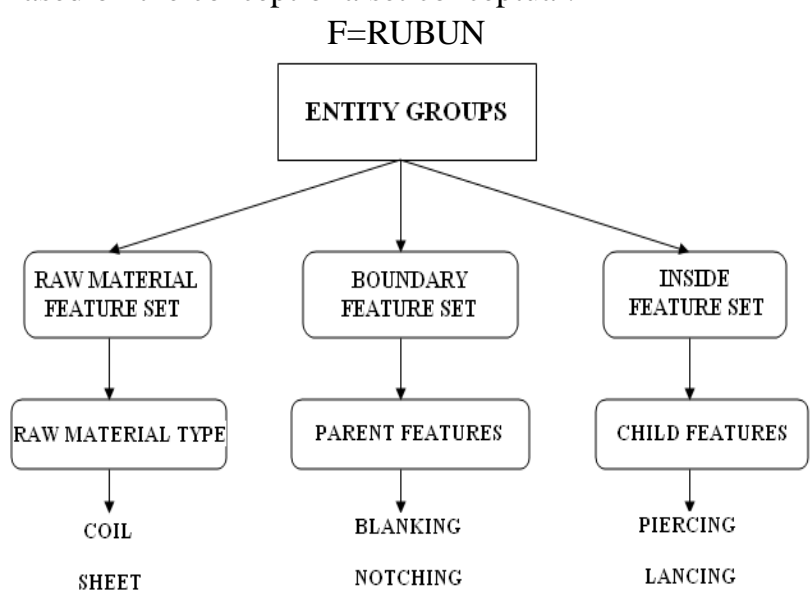

SHEET

NOTCHING

STRIP

Fig. 6.Classification scheme of group identification and product characteristics .

\section{Extraction of Adjacent mechanism as well as their Directions}

To find component design and identify different operation features, it needs neighboring components and paths. Cut, cut, slice, cut and slit. According to the Cartesian octants, the component element is calculated in eight different paths as shown in Figure 7.

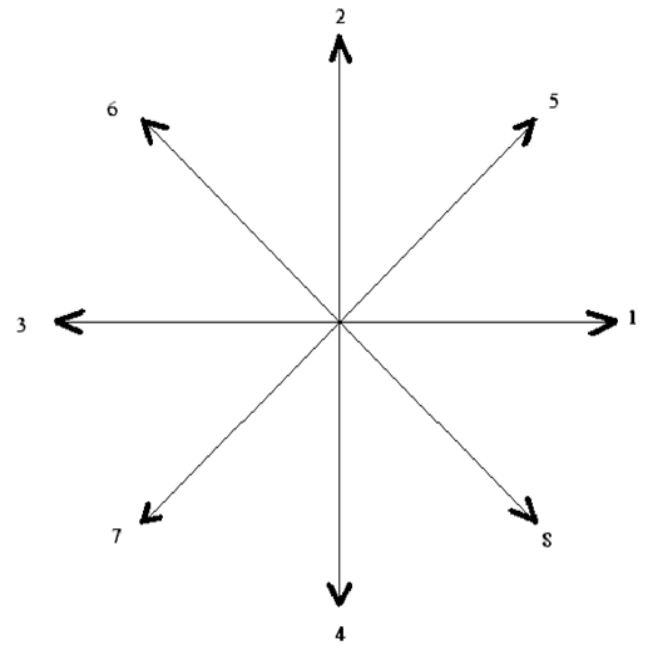

Fig. 7.Adjacency directions .

\section{RESULT AND DISCUSSION}

\section{A. Description Of The Layout}

\footnotetext{
Part - Component layout

Units $-\mathrm{mm}$

Thickness $-1 \mathrm{~mm}$
}

Number of features - $13\left(1^{\prime}-13^{\prime}\right)$

Feature set of the raw material $(\mathrm{R})-\left\{1^{\prime}\right\}$

Set of boundary functions (B) before lexicographical ordering - $\left\{2^{\prime}, 3^{\prime}, 4^{\prime}, 5^{\prime}\right\}$

Set of boundary functions (B) after lexicographical ordering - $\left\{4^{\prime}, 5^{\prime}, 2^{\prime}, 3^{\prime}\right\}$

Inside feature set $(\mathrm{N})-\left\{6^{\prime}, \ldots, 13^{\prime}\right\}$

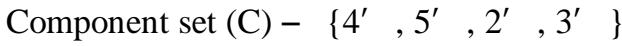

\section{B. Vertices List and ACDR Table}

Table I and Table II illustrates the vertices list and ACR table Table- I: Vertices list

\begin{tabular}{|c|c|c|c|c|c|}
\hline $\begin{array}{c}\text { Vertex } \\
\text { No. }\end{array}$ & $\mathbf{x}$ & $\mathbf{y}$ & $\mathbf{z}$ & $\mathbf{r}$ & $\begin{array}{l}\text { Bul } \\
\text { ge }\end{array}$ \\
\hline 1 & 74.53 & 249.60 & 0 & 0 & 0 \\
\hline 2 & 202.5 & 249.60 & 0 & 0 & 0 \\
\hline 3 & 202.5 & 103.60 & 0 & 0 & 0 \\
\hline 4 & 74.53 & 103.60 & 0 & 0 & 0 \\
\hline 5 & 94.0 & 242.0 & 0 & 0 & 0 \\
\hline 6 & 124 & 242.0 & 0 & 0 & 0 \\
\hline . & . & . & . & . & . \\
\hline 53 & 109 & 231.0 & 0 & 5 & 0 \\
\hline · & · & · & $\cdot$ & · & $\cdot$ \\
\hline
\end{tabular}

Table- II: ACDR table

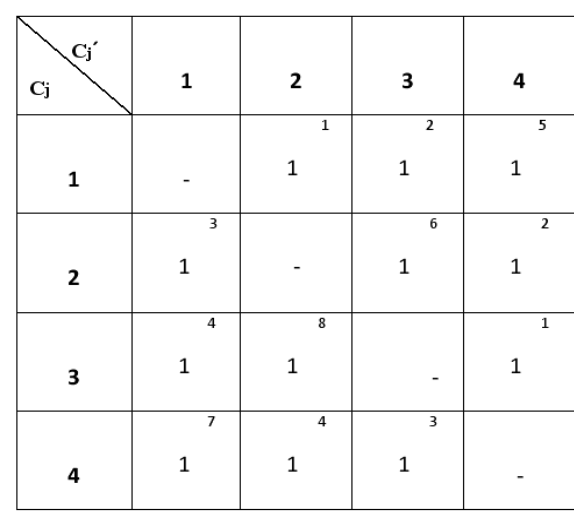

\section{Manufacturing Features}

Table III \& IV illustrates the piercing and Lancing.

Table- III: Piercing

\begin{tabular}{|c|c|c|c|}
\hline $\begin{array}{c}\text { Piercing } \\
\text { No. }\end{array}$ & $\begin{array}{c}\text { Component } \\
\text { No. }\end{array}$ & $\begin{array}{c}\text { Feature } \\
\text { No. }\end{array}$ & $\begin{array}{c}\text { Vertex } \\
\text { No. }\end{array}$ \\
\hline 1 & 1 & $8^{\prime}$ & 55 \\
\hline 2 & 2 & $9^{\prime}$ & 56 \\
\hline 3 & 3 & 6 & 53 \\
\hline
\end{tabular}




\begin{tabular}{|c|c|c|c|}
\hline 4 & 4 & $7^{\prime}$ & 54 \\
\hline \multicolumn{4}{|c|}{ Table- IV: Lancing } \\
\hline $\begin{array}{c}\text { Lancing } \\
\text { No. }\end{array}$ & $\begin{array}{c}\text { Component } \\
\text { No. }\end{array}$ & $\begin{array}{c}\text { Feature } \\
\text { No. }\end{array}$ & Vertex No. \\
\hline 1 & 1 & $12^{\prime}$ & $\begin{array}{c}79,80, \ldots \ldots, \\
89\end{array}$ \\
\hline 2 & 2 & $13^{\prime}$ & $\begin{array}{c}90,91, \ldots \ldots, \\
100\end{array}$ \\
\hline 3 & 3 & $10^{\prime}$ & $\begin{array}{c}57,58, \ldots \ldots \\
67\end{array}$ \\
\hline 4 & 4 & $11^{\prime}$ & $\begin{array}{c}68,69, \ldots \ldots, \\
78\end{array}$ \\
\hline
\end{tabular}

Table V and VI illustrates the Blanking and Shearing Table- V: Blanking

\begin{tabular}{|c|c|c|c|}
\hline $\begin{array}{c}\text { Blanking } \\
\text { No. }\end{array}$ & $\begin{array}{c}\text { Component } \\
\text { No. }\end{array}$ & $\begin{array}{c}\text { Feature } \\
\text { No. }\end{array}$ & $\begin{array}{c}\text { Vertex } \\
\text { No. }\end{array}$ \\
\hline 1 & 1 & $4^{\prime}$ & $\begin{array}{c}29,30, \ldots \ldots \\
40\end{array}$ \\
\hline 2 & 2 & $5^{\prime}$ & $\begin{array}{c}41,42, \ldots \ldots, \\
52\end{array}$ \\
\hline 3 & 3 & $2^{\prime}$ & $5,6, \ldots \ldots, 16$ \\
\hline 4 & 4 & $3^{\prime}$ & $\begin{array}{c}17,18, \ldots \ldots \\
28\end{array}$ \\
\hline
\end{tabular}

Table- VI: Shearing

\begin{tabular}{|c|c|}
\hline $\begin{array}{l}\text { Shearing } \\
\text { No. }\end{array}$ & Range $(1 \mathbf{x} 1-\mathbf{x} 21$ or $1 \mathbf{y} 1-y 21)$ \\
\hline 1 & $\begin{aligned} x 1 & =74.53553383432813 \\
x 2 & =82.53553383432813\end{aligned}$ \\
\hline 2 & $\begin{aligned} x 1 & =134.6066017177982 \\
x 2 & =144.6066017177982\end{aligned}$ \\
\hline 3 & $\begin{array}{l}x 1=194.5355338343281 \\
x 2=202.5355338343281\end{array}$ \\
\hline 4 & $\begin{array}{l}\mathrm{y} 1=103.6032949698677 \\
\mathrm{y} 2=111.6032949698677\end{array}$ \\
\hline 5 & $\begin{array}{l}\mathrm{y} 1=172.7867965644036 \\
\mathrm{y} 2=182.7867965644036\end{array}$ \\
\hline 6 & $\begin{array}{l}\mathrm{y} 1=241.6032949698677 \\
\mathrm{y} 2=249.6032949698677\end{array}$ \\
\hline
\end{tabular}

\section{CONCLUSION}

2D model preparation and diagram of a page metal constituent nested explain was carried out, and then Geometric information is collected from the DXF production file of AutoCAD by using ' $c$ ' programming. Creation of vertices list, ACDR table and formation of manufacturing features table are concluded. Identification of components and raw material type and Preparation of flowchart for manufacturing features. Creation of MER table and notching feature table. Apply the same method to different sheet metal components. By this, we can obtain different features for various sheet metal components.

\section{REFERENCES}

1. Z. Sukimin ,H. Haron,” Algorithm to Classify Features on DXF and Map the Feature of Machining Parameter", Asia Pasific Industrial Engineering \& Management Systems Conference, Vol. 3, Dec. 2008, pp. 2721-2728.

2. J. X. Gao ,Y. S. Tang, R. Sharma ," A feature model editor and process planning system for sheet metal products", Journal of Materials Processing Technology, Vol.107,No.1-3,Nov. 2000 ,pp.88-95.

3. H. M. Hussein, S. Kumar ," A computerized retrieval system for sheet metal parts", Asian International Journal of Science and Technology in Production and Manufacturing,Vol.1,No.2,2008,pp.31-40.
4. T. S. Kang , B. O. Nnaji ," Feature representation and classification for automatic process planning systems", Journal of manufacturing systems. Vol.12,No.2,Jan.1993,pp.133-45.

5. R. Jagirdar,V. K. Jain ,J. L Batra,S. G. Dhande," Feature recognition methodology for shearing operations for sheet metal components". Computer Integrated Manufacturing Systems,Vol.8,No.1,feb.1995,pp.51-62.

6. J. Senthil Kumar," FABRICATION OF HTC PLANT FOR CARBONISATION OF MUNICIPAL SOLID WASTE",International Journal of MC Square Scientific Research, Vol.9, No.1 April 2017,pp.26-33.

\section{AUTHORS PROFILE}

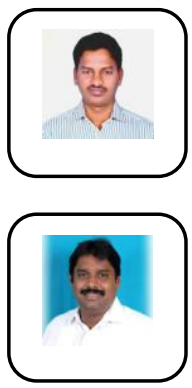

Vijayakumar K Assistant Professor, Department of Mechanical Engineering Aarupadai Veedu Institute of Technology Vinayaka Mission Research Foundation.vijayakumar@avit.ac.inwords.

L.Prabhu, Associate Professor, Department of Mechanical Engineering Aarupadai Veedu Institute of Technology, Vinayaka Mission Research Foundation.

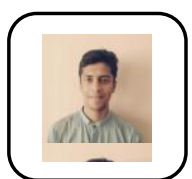

Tony O T, UG Student, Department of Mechanical Engineering Aarupadai Veedu Institute of Technology, Vinayaka Mission Research Foundation.

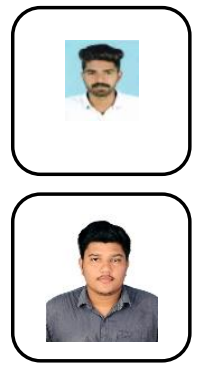

Akshith M S, UG Student, Department of Mechanical Engineering Aarupadai Veedu Institute of Technology, Vinayaka Mission Research Foundation.

Gokul Kannan, UG Student, Department of Mechanical Engineering Aarupadai Veedu Institute of Technology Vinayaka Mission Research Foundation. 